\title{
Review \\ Mouse models of breast cancer metastasis
}

\author{
Anna Fantozzi and Gerhard Christofori
}

\begin{abstract}
Institute of Biochemistry and Genetics, Department of Clinical-Biological Sciences (DKBW), Center of Biomedicine, University of Basel, Mattenstrasse 28, CH-4058 Basel, Switzerland
\end{abstract}

Corresponding author: Gerhard Christofori, gerhard.christofori@unibas.ch

Published: 26 July 2006

This article is online at http://breast-cancer-research.com/content/8/4/212

(c) 2006 BioMed Central Ltd

Breast Cancer Research 2006, 8:212 (doi:10.1186/bcr1530)

\begin{abstract}
Metastatic spread of cancer cells is the main cause of death of breast cancer patients, and elucidation of the molecular mechanisms underlying this process is a major focus in cancer research. The identification of appropriate therapeutic targets and proof-ofconcept experimentation involves an increasing number of experimental mouse models, including spontaneous and chemically induced carcinogenesis, tumor transplantation, and transgenic and/or knockout mice. Here we give a progress report on how mouse models have contributed to our understanding of the molecular processes underlying breast cancer metastasis and on how such experimentation can open new avenues to the development of innovative cancer therapy.
\end{abstract}

\section{Introduction}

Breast cancer is the most frequently diagnosed form of cancer and the second leading cause of death in Western women [1]. Death, and most of the complications associated with breast cancer, are due to metastasis developing in regional lymph nodes and in distant organs, including bone, lung, liver, and brain $[1,2]$. As in many other metastatic cancer types, specific molecular changes occurring within both the tumor cells and the tumor microenvironment contribute to the detachment of tumor cells from the primary tumor mass, invasion into the tumor stroma, intravasation into nearby blood vessels or lymphatics, survival in the bloodstream, extravasation into and colonization of the target organ and, finally, metastatic outgrowth $[3,4]$.

In the recent past, our understanding of breast cancer progression and metastasis has greatly profited from the use of genetically modified mouse models and advanced transplantation techniques. Here we describe the currently employed mouse models of breast cancer metastasis and how their use has contributed significantly to our understanding of the molecular processes underlying breast cancer metastasis.

\section{Mechanisms contributing to breast cancer metastasis}

A critical step towards the generation of mouse models of breast cancer is the understanding of the molecular pathways underlying mammary carcinogenesis. Our knowledge on how breast tumor progression occurs has also been markedly improved by unraveling the dynamics and the key factors of mammary gland development.

\section{Mammary gland development}

Mouse breast tissue undergoes continuous changes throughout the lifespan of reproductively active females, mediated mainly by interactions between the mammary epithelium and the surrounding mesenchyme (Figure 1). The mammary bud develops by forming a network of branched ducts invading into the mammary fat pad [5]. With the release of ovarian hormones, terminal end buds are formed. They represent the invading front of the ducts and they are able to proliferate, to extend into the fat pad, and to form branches. During pregnancy and lactation, hormone-induced terminal differentiation of the mammary epithelium into milk-secreting lobular alveoli takes place. After weaning, the secretory epithelium of the mammary gland involutes into an adult nulliparous-like state by apoptosis and redifferentiation. During these processes, the developing mammary gland has the ability to induce angiogenesis to adjust for blood supply and is protected against premature involution; it is therefore resistant to apoptosis [6]. Interestingly, proliferation, invasion, angiogenesis, and resistance to apoptosis are all features that are abused during the etiology of breast carcinogenesis.

$\mathrm{COX}=$ cyclo-oxygenase $\mathrm{CSF}=$ colony-stimulating factor; $\mathrm{CTGF}=$ connective tissue growth factor; $\mathrm{ECM}=$ extracellular matrix EGF $=$ epidermal growth factor; EMT = epithelial-mesenchymal transition; IGF = insulin-like growth factor; IL = interleukin; MEKK = MAP kinase/ERK kinase kinase; $\mathrm{MMP}=$ matrix metalloproteinase; MMTV = murine mammary tumour virus; PTHrP = parathyroid hormone-related protein; PyMT = polyoma middle T antigen; SDF $=$ stromal cell-derived factor; TGF $=$ transforming growth factor; VCAM $=$ vascular cell adhesion molecule; VEGF $=$ vascular endothelial growth factor. 


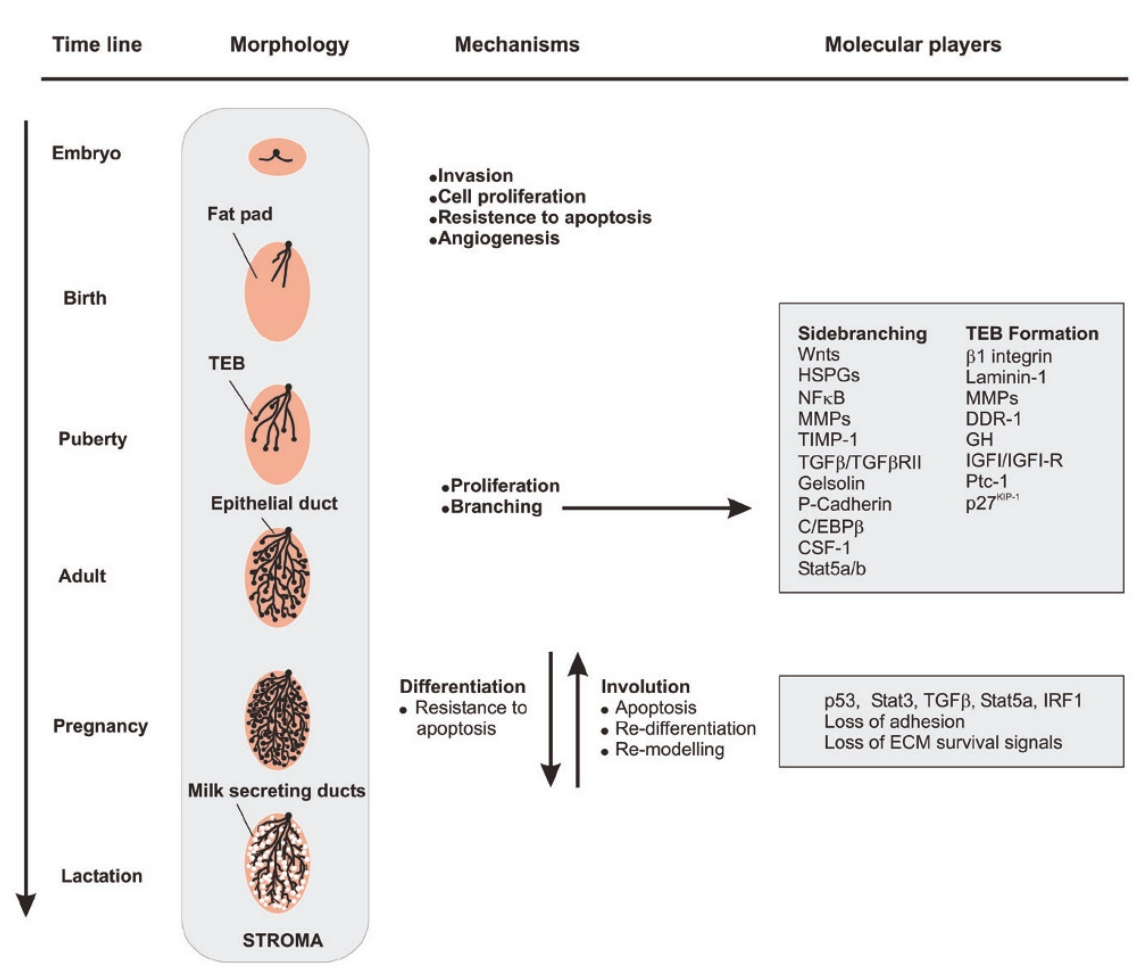

Schematic representation of epithelial-stromal interactions during mammary gland development. The mammary bud originates at the embryonic level and starts proliferating after birth. Pubertal hormones drive the invasion of the fat pad by the generation of epithelial ducts and terminal end buds (TEB). Proliferation and side branching continues until epithelial ducts fill the adult mammary gland. Pregnancy hormones induce the full development and proliferation of the mammary gland and the transformation of the lobular alveoli into milk-secreting ducts. After lactation the mammary gland involutes to return to a nulliparous-like state via apoptosis, redifferentiation and remodeling processes. C/EBP, CCAAT-enhancerbinding protein; CSF, colony-stimulating factor; DDR, discoidin domain receptor; ECM, extracellular matrix; HSPG, heparan sulfate proteoglycan; $\mathrm{GH}$, growth hormone; IGF, insulin-like growth factor; IRF, interferon regulatory factor; MMP, matrix metalloproteinase; NFKB, nuclear factor- $\mathrm{KB}$; Ptc-1, patched-1; TGF, transforming growth factor; TIMP, tissue inhibitor of metalloproteinases.

\section{Transformation and metastasis}

Mammary gland morphogenesis and branching involve the regulatory function of several signaling pathways, including signaling by Wnt family members [7], transforming growth factor- $\beta$ (TGF- $\beta$ ) [8], insulin-like growth factor-I (IGF-I) [9], and epidermal growth factor (EGF) and others [10]. These pathways are frequently activated during the tumorigenic process by mutation or gene amplification, thus allowing the mammary epithelium to expand, proliferate, and invade neighboring tissue. The cross-talk and interactions between tumor cells and the surrounding stroma, the extracellular matrix (ECM), and infiltrating cells of the immune system are constantly modulating tumor development. The mammary stroma, composed of pre-adipocytes, adipocytes, fibroblasts, endothelial cells, and inflammatory cells, contributes functionally to mammary gland development [6]. In a similar manner, tumor-stroma interactions, occurring via soluble growth factors, cytokines and chemokines, remodeling of the extracellular matrix, or direct cell-cell adhesion, are critical for tumor growth, migration, and metastasis. Alteration of the expression or function of adhesion molecules responsible for the adhesion of breast cancer cells to themselves, to stromal cells, or to tumor matrix, including integrin family members, immunoglobulin-domain cell adhesion molecules (such as L1 and NCAM), cadherin family members, or other cell surface receptors (such as CD44), contributes predominantly to latestage tumor progression and metastatic dissemination of cancer cells $[11,12]$.

The formation of new blood vessels (angiogenesis) is crucial for the growth and persistence of primary solid tumors and their metastases, and it has been assumed that angiogenesis is also required for metastatic dissemination, because an increase in vascular density will allow easier access of tumor cells to the circulation. Induction of angiogenesis precedes the formation of malignant tumors, and increased vascularization seems to correlate with the invasive properties of tumors and thus with the malignant tumor phenotype [13]. In fact, angiogenesis indicates poor prognosis and increased risk of metastasis in many cancer types, including breast cancer [14]. With the recent identification of lymphangiogenic factors and their receptors it has also been possible to 
investigate the causal role of lymphangiogenesis in the metastatic process (reviewed in [15]). It is therefore not surprising that molecules essential for mammary gland development, many of them stromal factors, are also critical participants in breast carcinogenesis.

The knowledge gained on the several mechanisms contributing to tumor progression can be used to design and generate better mouse models. At the same time, such models allow a thorough investigation of all different aspects of multistage breast carcinogenesis, including the genetic alterations leading to tumor onset, neovascularization, tumor progression, and formation of metastasis in secondary organs.

\section{Breast cancer metastasis models Tumor transplantation}

There are various ways to mimic breast cancer growth and metastasis in tumor transplantation experiments. The site of injection, together with the specific tropism of the chosen breast cancer cell line used, largely defines primary and secondary metastatic growth. Orthotopic or ectotopic implantation of cancer cells in the skin or mammary fat pad, with the formation of primary tumors and the subsequent formation of metastasis, in part resembles the multiple stages involved in malignant breast cancer development in patients [16]. In contrast, tail vein injection results mainly in lung metastasis, whereas portal vein injection provokes colonization of the liver, and intracardiac infusion gives rise to a broader target organ spectrum, including bone. Notably, the direct introduction of cancer cells into the blood circulation should be considered an assay of organ colonization and not a true metastatic process.

Depending on the species or genetic background of donor and host, syngeneic or xenograft tumor transplantations need to be distinguished. Transplantation of cancer cells from one mouse into another mouse with identical genetic backgrounds (syngeneic transplantation) bypasses the immunologic host-versus-graft reaction and concomitantly allows the investigation of the contribution of an intact immune system to malignant tumor progression $[17,18]$. Syngeneic mouse models have been employed to establish organ-specific metastasis models by several rounds of transplantation/ metastasis formation and the selection of metastatic cell lines in vivo [19]. For example, 4T1 cells, which originally derive from a spontaneous mouse mammary tumor of a BALB/C mouse, grow rapidly when injected into the fat pad of a syngeneic animal and metastasize to lungs, liver, bone, and brain $[19,20]$. Sublines of 4 T1 cells, which exhibit various degrees of metastatic dissemination, have been employed recently to generate distinct gene expression signatures for each stage of tumor progression, namely primary tumor formation, lymph node colonization, metastatic outgrowth in the lymph node, and distant organ metastasis. These experiments led to the identification of the transcriptional repressor
Twist, some members of the cadherin family of cell-cell adhesion molecules, and various chemokines as critical factors in the distinct stages of metastatic tumor progression [20]. This and other syngeneic mouse models have also been successfully employed for the testing of experimental drugs designed to interfere with tumor malignancy $[18,21]$.

To investigate the growth and metastasis of human breast cancer cell lines in vivo, xenograft transplantation experiments are performed in immunocompromised mice [22]. Human breast cancer cells can be injected subcutaneously, intravenously, intracardially, or orthotopically into the fat pad of the mouse [23]. For example, MDA-MB-231 cells, an estrogen-independent breast cancer cell line derived from the pleural effusion of a cancer patient, is able to colonize bone, liver, lung, adrenal glands, ovary, and brain after intravenous injection [24]. This cell line and organ-specific metastatic variants thereof have recently been used to identify and functionally implicate a number of genes in organ-specific metastasis, including IL-11, osteopontin and the connective tissue growth factor (CTGF) in osteolytic metastasis [25,26], and epiregulin, CXCL1, matrix metalloproteinase-1 (MMP-1), cyclo-oxygenase-2 (COX-2), inhibitor of differentiation-1 (Id1) and others in lung metastasis [27] (see below).

The implantation of established cell lines derived from human breast cancer is relatively simple and allows the genetic or pharmacological manipulation of the implanted cells. However, there are clear limitations to xenograft models. First, immune responses, which have a key role during tumor development, are impaired in immunocompromised mice. Second, stromal components are not of tumor origin. For example, carcinoma-associated fibroblasts derived from a breast cancer patient support the growth of a breast carcinoma cell line better than the normal tissue in a xenograft mouse co-implantation model. Carcinoma-associated fibroblasts seem to activate and sustain CXCR4/stromal cell-derived factor (SDF-1)-mediated chemokine signaling and to recruit endothelial progenitors to the growing tumor, thereby promoting angiogenesis [28,29]. Last, human cells are apparently not fully adapted to grow in a murine environment. For example, breast cancer metastasis to bone has recently been investigated in an experimental mouse system in which both the breast cancer cells and the metastatic target organ, the bone, are of human origin [30]. After orthotopic injection, cancer cells predominantly colonize the bone of human origin, thus exhibiting a species-specific osteotropism.

\section{Genetically modified mice}

Several promoters can be used to drive the expression of transgenes in the mammary epithelium (Table 1), and many known oncogenes have been expressed under their control to initiate or modulate breast carcinogenesis in mice, including ErbB2/Neu, polyoma middle $\mathrm{T}$ antigen (PyMT), simian virus 40 (SV40) $\mathrm{T}$ antigen, Ha-Ras, Wnt-1, TGF- $\alpha$, and c-Myc. MMTV-Neu and MMTV-PyMT transgenic mice (in 
Table 1

\begin{tabular}{|c|c|c|c|c|}
\hline Promoter & Origin & Expression & Activation & References \\
\hline MMTV-LTR & Mouse mammary tumor virus & $\begin{array}{l}\text { Breast epithelial cells, several } \\
\text { other tissues }\end{array}$ & Steroid hormones & {$[42]$} \\
\hline WAP & Whey acidic protein & Secretory mammary epithelium & Lactogenic hormones & {$[96,97]$} \\
\hline С3(1) & $\begin{array}{l}\text { Rat prostate steroid-binding } \\
\text { protein (PSBP) }\end{array}$ & $\begin{array}{l}\text { Epithelial cells of prostate and } \\
\text { mammary gland }\end{array}$ & $\begin{array}{l}\text { Estrogen (ductal and alveolar } \\
\text { mammary epithelium) }\end{array}$ & [36] \\
\hline B-LG & Bovine $\beta$-lactoglobulin & Mammary gland & Pregnancy and lactation & {$[98,99]$} \\
\hline MT & Metallothionein & Most mammary cells & $\mathrm{Zn}^{2+}$ & {$[100]$} \\
\hline
\end{tabular}

which the expression of the oncogene is driven by the Mouse Mammary Tumor Virus promoter) develop metastasis in lung and lymph nodes, mainly after their first pregnancy, while other transgenic mice have to be combined to generate double-transgenic mice that efficiently develop malignant cancers [31-35]. C3(1)-SV40 T-antigen transgenic mice develop invasive mammary carcinomas independently of hormone supplementation or pregnancy, with a $15 \%$ incidence of lung metastasis. This model recapitulates the loss of estrogen receptor- $\alpha$ expression that is frequently observed in human breast cancer [36]. The most commonly used transgenic mouse models that develop metastatic mammary cancer are summarized in Table 2.

Investigating the functional role of distinct genes during the multiple stages of breast carcinogenesis requires the ability to modulate their function in time and space [37]. Inducible transgene expression can be obtained by the use of the bacteria-derived tetracycline-inducible system permitting the switching on or off (Tet-On/Tet-Off system) of a gene of interest in a tissue- and time-specific manner [38]. In contrast, mice are modified by the genetic ablation of a gene of interest in an inducible manner to generate conditional knockouts with the use of the Cre/loxP phage recombinase system, for example [39]. To ablate a gene at a certain time point in mammary epithelial cells, recombinase activity can be controlled by the expression of a tamoxifen-inducible version of Cre (MMTV-ER ${ }^{\text {TM}}$-Cre) or by using the tetracyclineinducible system to drive Cre expression [40].

First comparisons of gene expression profiles obtained from mammary gland tumor models initiated by different oncogenes have revealed several common and oncogene-specific targets and similarities with human molecular breast cancer pathology [41]. The challenge now is to test whether genes identified in gene expression profiling experiments with patient samples are able to modulate breast carcinogenesis in transgenic mouse models, for example in the wellcharacterized MMTV-Neu and MMTV-PyMT mouse models of breast carcinogenesis or in improved versions of these.

\section{MMTV-Neu}

Amplification of the gene encoding ErbB2, a member of the EGF receptor gene family, is associated with 15 to $20 \%$ of human breast cancers, and in about 30\% of cases the increased expression of an activated form of ErbB2 is detected. Consistent with this notion is the observation that transgenic expression of an activated form of the rat homolog of ErbB2 (Neu) in MMTV-Neu transgenic mice results in the development of multifocal adenocarcinomas with lung metastases at about 15 weeks after pregnancy [42]. Transgenic expression of wild-type ErbB2 in mammary gland also provokes tumor formation and metastatic dissemination, yet with longer latency.

Doxycycline-inducible expression of ErbB2 in mammary epithelial cells of transgenic mice also results in invasive mammary carcinoma and extensive metastasis, yet the tumors regress with the loss of ErbB2 expression upon the withdrawal of doxycycline. However, most mice exhibit recurrences of the tumors [43]. These recurrent tumors exhibit epithelial-mesenchymal transition (EMT), which seems to be mediated by the upregulated expression of the transcriptional repressor Snail, a molecular process that seems to have a high prognostic value in predicting human breast cancer recurrence. Expression of oncogenic versions of ErbB2 that bind either Grb-2 or Shc demonstrate that focal mammary tumors with a high rate of lung metastasis require Grb-2-mediated signaling, whereas low metastatic multifocal mammary tumors rely on Shc function [44].

\section{MMTV-PyMT}

Mammary gland-specific expression of PyMT under the control of the MMTV promoter/enhancer in transgenic mice (MMTV-PyMT) results in widespread transformation of the mammary epithelium and in the development of multifocal mammary adenocarcinomas and metastatic lesions in the lymph nodes and in the lungs [45]. Tumor formation and progression in these mice is characterized by four stages: hyperplasia, adenoma/mammary intra-epithelial neoplasia, and early and late carcinoma [46]. The close similarity of this 
Table 2

\begin{tabular}{|c|c|c|c|c|c|c|c|}
\hline TG mouse model & Expression & $\begin{array}{c}\text { Tumor } \\
\text { incidence } \\
(\%)\end{array}$ & $\begin{array}{c}\text { Tumor } \\
\text { latency } \\
\text { (months) }\end{array}$ & $\begin{array}{l}\text { Metastasis } \\
\text { incidence } \\
(\%)\end{array}$ & $\begin{array}{l}\text { Metastatic } \\
\text { site }\end{array}$ & $\begin{array}{l}\text { Metastasis } \\
\text { latency } \\
\text { (months) }\end{array}$ & References \\
\hline \multicolumn{8}{|l|}{ Single-transgenic mice } \\
\hline MMTV-Cox2 & Mammary gland & $>85$ & $7^{\mathrm{a}}$ & b & LN & & [101] \\
\hline MMTV-Wnt1 & Mammary gland & 60 & 8 & b & Lung, LN & & {$[7,16,77]$} \\
\hline MMTV-Neu & Mammary gland & 100 & $6.8^{\mathrm{a}}$ & 72 & Lung & 8 & {$[16,102]$} \\
\hline MMTV-Neu activated & Mammary gland & 100 & $3^{\mathrm{a}-5}$ & 20 & Lung & 3.5 & {$[42,44]$} \\
\hline MMTV-Neu (YB) & Mammary gland & 100 & $6^{a}$ & 65 & Lung & 2 & {$[44,67]$} \\
\hline MMTV-Neu (YD) & Mammary gland & 100 & $3.6^{\mathrm{a}}$ & 44 & Lung & 2 & \\
\hline MMTV-РyMT & Mammary gland & 100 & $1-6$ & $>85 ; 51$ & Lung; LN & 3.5 & {$[16,45,51]$} \\
\hline MTB-TAN & Mammary gland & 100 & - & 92 & Lung & & {$[16,103]$} \\
\hline MT-Met & Mammary gland & $\mathrm{b}$ & 10 & $\mathrm{~b}$ & $\begin{array}{l}\text { Lung; LN; kidney; } \\
\text { heart; cecum }\end{array}$ & & {$[16,104]$} \\
\hline С3(1)-Tag & Mammary gland & 100 & $3-6$ & $\mathrm{~b}$ & Lung & & {$[16,105]$} \\
\hline Wap-Notch4 & Mammary gland & 100 & 6.2 & High & Lung & & [106] \\
\hline Wap-T-NP & Mammary gland & $12-83$ & 11 & b & Lung, LN & & [107] \\
\hline Wap-Ras & $\begin{array}{l}\text { Mammary gland, } \\
\text { salivary gland }\end{array}$ & 100 & 6 & 14 & Lung & & {$[16,108]$} \\
\hline Wap-HGF & Mammary gland & 89 & $1-2$ & 22 & Lung & $1-2$ & [109] \\
\hline H19-IGF2 & Mammary gland & $50-100$ & $>9$ & 38 & Lung, spleen; liver & & {$[16,110]$} \\
\hline \multicolumn{8}{|l|}{ Composite-transgenic mice } \\
\hline p53fp/fp MMTV-Cre Wap-Cre & Mammary gland deletion & 100 & $10-18^{a}$ & 50 & Lung, liver & & [111] \\
\hline p53 $3^{+/-}$MMTV- $\Delta \mathrm{N}-\beta$-catenin & Mammary gland & 100 & $9.8^{\mathrm{a}}$ & 39 & Lung & & [112] \\
\hline CD44-/-MMTV-PyMT & Mammary gland & 100 & $3.5^{a}$ & 66 & Lung & 3.5 & [12] \\
\hline MMTV-Neu;SR2F & Mammary gland & 86.8 & $8^{a}$ & 12 & Lung & & [70] \\
\hline MMTV-NeuYB;TßRI(AAD) & Mammary gland & & $8.9^{a}$ & 65 & Lung & 2 & {$[67]$} \\
\hline MMTV-NeuYD;TßRI(AAD) & Mammary gland & & $4.4^{\mathrm{a}}$ & 44 & $>$ Extravascular & & \\
\hline MMTV-NeuYB;T $\beta R \|(\triangle C y t)$ & Mammary gland & & $6^{\mathrm{a}}$ & 65 & $<$ Extravascular & & \\
\hline $\begin{array}{l}\text { MMTV-rtTA/TetOp-TGF- } \\
\beta 1 S 223 / 225 ; \text { MMTV-PyMT }\end{array}$ & Mammary gland & & $1.8^{\mathrm{a}}$ & $>10$-fold & Lung & 3.2 & [68] \\
\hline MMTV-Neu; S100A4 & Mammary gland & & 12 & 50 & Lung & & {$[16,113]$} \\
\hline MMTV-Wnt1; int2 & Mammary gland & 90 & $4^{\mathrm{a}}$ & b & Lung, LN & & {$[7,77]$} \\
\hline MMTV-PyMT; uPA-/- & Mammary gland & 100 & $1.5^{\mathrm{a}}$ & 31 & Lung, LN & 3.5 & {$[45,51,52]$} \\
\hline MMTV-PyMT; $\mathrm{Plg}^{-/-}$ & Mammary gland & 100 & $1.5^{\mathrm{a}}$ & $25^{c}$ & Lung & 3 & \\
\hline MMTV-PyMT; VEGF & Mammary gland & 100 & $1-2$ & 100 & Lung & 2 & [91] \\
\hline MMTV-PyMT; MEKK1-/- & Mammary gland & 100 & 3 & 25 & Lung & 4 & [53] \\
\hline
\end{tabular}

aTumor $t_{50}$ was reported; bmetastasis/tumor appearance but not incidence was reported; clung metastasis in all Plg ${ }^{-/-}$mice analyzed versus $56 \%$ in control mice; metastasis was dependent on tumor burden. HGF, hepatocyte growth factor; LN, lymph nodes.

model to human breast cancer is also exemplified by the fact that in these mice a gradual loss of steroid hormone receptors (estrogen and progesterone) and $\beta 1$-integrin is associated with overexpression of ErbB2 and cyclin D1 in late-stage metastatic cancer [47]. The MMTV-PyMT mouse model of breast cancer is furthermore characterized by short 
latency, high penetrance, and a high incidence of lung metastasis occurring independently of pregnancy and with a reproducible kinetics of progression.

In MMTV-PyMT transgenic mice, increased metastatic potential has been shown to depend on the presence of macrophages in primary tumors and on the establishment of a chemoattractant paracrine loop of colony-stimulating factor-1 (CSF-1) and EGF ligands between macrophages and tumor cells $[48,49]$. In MMTV-PyMT/CSF-1-/- mice, tumor progression and metastasis are significantly delayed but restored on the overexpression of CSF-1 in the mammary gland $[48,50]$. The crucial role of macrophages in sustaining tumor progression was further shown by depletion of plasminogen, a downstream effector of CSF-1, either by its genetic ablation or by affecting the expression of its activator UPA, resulting in significantly reduced metastasis in the MMTV-PyMT mouse model without affecting primary tumor growth [51,52]. The uPA/plasminogen system may contribute to metastasis mainly by ECM degradation. The relevance of this mechanism is further supported by experiments with MEKK1-deficient MMTV-PyMT mice, which show a significant delay in lung metastasis, whereas no differences are observed in the primary tumor growth. MEKK1 signaling is involved in cell adhesion and controls uPA induction. Accordingly, MEKK1deficient mice display decreased levels of uPA, which result in reduced levels of activated plasminogen and impaired tumor cell migration and invasiveness [53].

The role of adhesion molecules during mammary gland tumor progression has also been addressed with the use of MMTVPyMT mice. Specifically, loss of CD44 promotes lung metastasis in these mice, highlighting the role of tumor-stroma interaction for adhesion and invasion [12]. CD44 expression on tumor cells mediates their interaction with hyaluronanexpressing stromal cells and results in increased cancer progression. Loss of another adhesion molecule, Muc-1, in the MMTV-Wnt1 tumor model results in a delayed onset of tumorigenesis as well as delayed metastasis to lungs. Muc-1 seems to form complexes with $\beta$-catenin at the cell membrane and in the cytoplasm of cells at the tumor's invading front [54].

Recent results indicate that changes in cell adhesion have a critical function in tumor progression [11]. For example, the epithelial adherens junction molecule E-cadherin is considered a tumor and invasion suppressor. Forced expression of E-cadherin prevents tumor cell migration and invasion, whereas inhibition of E-cadherin function enhances tumor cell invasion and metastatic dissemination. E-cadherin is irreversibly lost in more than $85 \%$ of invasive lobular breast cancer associated with an invasive phenotype, and in the remaining $15 \%$ the retention of E-cadherin is associated with dysfunctional adhesion. Interestingly, a transgenic mouse model of epithelial loss of both E-cadherin and p53 develops metastatic mammary carcinoma resembling human invasive lobular breast cancer (J. Jonkers, personal communication).
Taken together, these examples indicate that transgenic mouse models of breast cancer metastasis are essential to understanding the role of several molecules in modulating key steps during malignant progression.

\section{In vivo imaging}

Non-invasive in vivo imaging techniques have been developed to reveal metastatic mammary tumors in experimental systems. Cell lines and transgenic mice can be engineered to express luminescent or fluorescent markers, permitting the visualization of primary tumor growth and the formation of metastatic nodes in live animals over time. MMTV-enhanced green fluorescent protein (eGFP) mice or mice in which expression of eGFP or luciferase marker genes is 'switched on' in the mammary gland in a Cre-dependent way upon crossing with either WAP-Cre or MMTV-Cre mice have been generated [55-57]. Tumor growth and metastasis formation can be easily monitored in composite transgenic animals after crossing of these mice with breast cancer mouse models [58]. Moreover, tumor progression and the actual metastatic mobility of tumor cells can be detected in live animals by multiphoton microscopy, positron-enhanced tomography scans, and magnetic resonance analysis [59-61]. Furthermore, the newest technologies, including intravital microscopy [62,63], in vivo flow cytometry [64], and multicolor fluorescent-based approaches, provide the possibility of quantitatively detecting individual tumor cells in living animals and documenting their clearance, motility, and migration to or retention in target organs.

\section{Molecular pathways dissected using breast cancer mouse models Transforming growth factor- $\beta$}

TGF- $\beta$ exerts a dual role during tumor progression: by inducing the expression of cell cycle inhibitors, it acts as a tumor suppressor during the initial phases of tumor progression. Yet it promotes metastasis and invasion in the later stages by inducing EMT [8]. The role of TGF- $\beta$ in breast cancer metastasis is still under investigation. One of its major functions, beside the induction of EMT, is inducing the migration and intravasation of breast cancer cells into the circulation, thereby promoting osteolytic metastasis [65]. Expression of TGF- $\beta 1$ in double-transgenic MMTV-Neu/ MMTV-TGF- $\beta 1$ mice increased the number of cancer cells circulating in the blood as well as the lung metastases, whereas primary tumors developed at unchanged frequency $[66,67]$. Inducible expression of TGF- $\beta 1$ in mammary glands of MMTV-PyMT transgenic mice also demonstrated the prometastatic function of TGF- $\beta 1$ [68]. Transgenic mice expressing TGF- $\beta \mathrm{RI}$ or a dominant-negative version of TGF- $\beta$ RII under the control of the MMTV promoter crossed with MMTV-Neu mice promoted and repressed, respectively, tumor metastasis [44]. Surprisingly, conditional knockout of TGF- $\beta R$ II in the mammary epithelium of the MMTV-PyMT mouse resulted in increased metastasis formation [69]. Together, these experiments in mouse models demonstrate 
the pivotal role of TGF- $\beta$ signaling in breast carcinogenesis. These observations have implications for the development of anti-metastatic therapies. For example, long-term treatment of MMTV-Neu mice with a soluble version of TGF- $\beta$ RII protects MMTV-Neu mice from metastasis without increasing primary tumor growth, hence selectively blocking the metastatic effects of TGF- $\beta$ while not affecting its functions in early tumor stages [70]. Chronic exposure to the soluble TGF- $\beta$ RII in these mice did not cause any unwanted side effects, suggesting a potential avenue for the development of therapy. Small inhibitors of the TGF- $\beta$ receptor kinase activity and agents specifically blocking TGF- $\beta$-mediated signaling pathways are currently in clinical trials [71].

\section{EGF family members}

The importance of TGF- $\alpha$, an EGF family member, in mammary tumor onset has been demonstrated by the transgenic expression of TGF- $\alpha$ under the control of several mammary epithelium-specific promoters. Such tissue-specific expression has led to distorted mammary gland development. However, primary tumors and pulmonary metastasis formed only after the combination of several additional tumor-promoting factors, such as crossing TGF- $\alpha$ transgenic mice with MMTVMyc transgenic mice or treating MMTV-TGF- $\alpha$ mice with chemical carcinogens. In double-transgenic MMTV-TGF- $\alpha$; MMTV-TGF- $\beta$ mice, tumor development is, however, suppressed [72].

We have already introduced the importance of ErbB2 in breast carcinogenesis. In addition, amplification of the gene encoding EGFR correlates with increased metastasis and is a bad prognosis factor in breast cancer [73]. MMTV-Neu mice have also been extensively employed to investigate the functional contribution of EGFR to mammary carcinogenesis. EGFR-mediated signaling contributes to invasion, intravasation and metastasis, along with the mitogenic signaling in this model [49,74,75]. Moreover, EGFR contribution to metastasis was shown by using MTLn3 rat mammary adenocarcinoma cells injected into the fat pad of mice. By quantifying the number of tumor cells in the blood as a direct measure of cell intravasation it was possible to show that EGFR acts via increased cell motility and intravasation rather then by affecting cell proliferation [76]. A neutralizing antibody against ErbB2 (Herceptin) has been developed to repress the tumorigenic stimuli of $\mathrm{ErB2}$ and has been approved for clinical use (reviewed in [10]). Together with newly developed inhibitors of EGFR signaling, combinatorial repression of EGFR and ErbB2 activity may therefore be an efficient way to combat breast cancer.

\section{Wnt signaling}

Wnt family members were the first proto-oncogenes to be discovered by an MMTV-mediated insertion-activation mechanism. Transgenic expression of Wnt-1 in the mammary gland of transgenic mice results in mammary adenocarcinomas with metastasis to lymph nodes and lungs [7].
Moreover, Wnt-1 collaborates with fibroblast growth factor-3, another MMTV-insertion-activated gene, in tumor onset. Surprisingly, in double-transgenic MMTV-Wnt-1;MMTV-TGF- $\beta$ animals, tumor cell proliferation is not repressed by TGF- $\beta$ expression, showing an opposite effect to that observed for MMTV-TGF- $\alpha$;MMTV-TGF- $\beta$ mice (see above) [77].

\section{Genes involved in organ-specific metastasis}

Cancers developing in a certain organ usually exhibit particular patterns of organ-specific metastasis. Breast cancer predominantly colonizes bone, followed by axillary and other lymph nodes, lung, liver, brain, and (rarely) adrenal glands. A combination of physical factors, such as lymphatic and blood vessel capillary networks encountered by disseminating tumor cells, and environmental factors, such as chemoattractive cytokines or chemokines and the presence of 'vasculature addresses', contribute to the specific dissemination of metastastic cancer cells $[78,79]$. One possible underlying mechanism is that breast cancer cells follow a cytokine gradient by co-opting immune cells' strategies to arrive at target organs [80].

Xenograft transplantation experiments using the MDA-MB231 cell line have been instrumental in demonstrating the functional role of certain genes in organ-specific breast cancer metastasis. For instance, prevention of CXCR4 expression by using short interfering RNA technology or blocking its function with specific antibodies or synthetic peptides repressed the formation of lung metastasis, indicating that the CXCR4 ligand, SDF-1, expressed by metastatic target organs, is recruiting tumor cells via CXCR4, which is expressed on breast cancer cells [80-82]. Orthotopic, intracardiac, and tail vein injections of MDA-MB231 cells have also been performed to identify genes modulating organ-specific metastasis, for example to bone or lung [25,27]. Gene expression profiling experiments with sublines of MDA-MB-231 selected for organ-specific metastasis have identified specific gene expression signatures for different organ-specific metastases. The functional involvement of these genes and factors in directing organ-specific metastasis was demonstrated subsequently. Genes involved in lung metastasis include those encoding the EGF-like factor epiregulin, CXCL1, MMP-1 and MMP-2, SPARC, vascular cell adhesion molecule-1 (VCAM-1), Id1, and COX-2, and genes promoting bone metastasis include those encoding IL-11, osteopontin, CTGF, CXCR4, and MMP-1 [25,27].

Overexpression of osteopontin induces metastasis of poorly metastatic MDA-MB-231 cells, whereas its downregulation is correlated with reduced osteolytic metastasis [26]. Osteopontin upregulates uPA plasminogen activator, which, upon binding to integrins and surface receptors, provokes the activation of both the hepatocyte growth factor (HGF) and EGF pathways [83]. Xenograft transplantation of MT2994 primary breast cancer cells has shown that the expression of osteopontin was associated with a constitutive activation of 
the phosphoinositide 3-kinase pathway and a metastatic phenotype of tumor cells [74]. Moreover, osteopontin can induce the expression of alternatively spliced isoforms $v 6$ and v9 of CD44 in breast cancer cells, leading to an increase in cell migration [84].

In a similar approach, sublines of the breast cancer cell line MDA-MB-435 have been selected for specific colonization of lung, lymph node, and thorax. Several adhesion and matrix molecules are correlated with lymph node metastasis, including CD73, a cell surface protein previously implicated in lymphocyte homing to lymph nodes [85]. Moreover, MDA-MB-468 variant metastatic cells with tropism to lymph nodes may use differential expression of adhesion molecules and may mimic angiogenesis pathways to reach lymph nodes [86]. Notably, these cells express $\alpha 9 \beta 1$ integrin, an integrin that is specifically expressed on lymphatic endothelial cells and can bind many ligands previously implicated in metastasis, including osteopontin, tenascin C, VCAM-1 and the lymphangiogenic factors vascular endothelial growth factor (VEGF)-C and VEGF-D.

Recent work has documented a role for RANK/RANK ligand (RANKL) signaling together with parathyroid hormone-related protein (PTHrP) and osteoprotegerin in bone metastasis. Treatment with a humanized antibody against PTHrP significantly suppressed osteolytic metastasis in mice injected with a subline of MDA-MB-231 that showed high metastatic ability to bone and expressed high levels of PTHrP, IL-8, IL-6, and MMP-1 [87]. The importance of the role of RANK/RANKL signaling in the regulation of tumor cell migration has also been reported for melanoma cells in vivo [88], whereas experiments performed with MDA-MB-231 breast cancer cells have shown that the RANK soluble receptor, osteoprotegerin, is effective in specifically decreasing bone metastasis by preventing the signaling that mediates the differentiation and activation of osteoclasts [89]. However, in an intra-tibial ectotopic injection model of osteoprotegerin and PTHrP overexpression by MCF-7 breast cancer cells it was revealed that overexpression of osteoprotegerin by tumor cells actually supports tumor growth [90].

Upregulated expression of VEGF-C, and to a smaller extent that of VEGF-D, is highly correlated with lymphangiogenesis and lymph node metastasis in cancer patients. Moreover, forced expression of VEGF-C or VEGF-D in tumor cell lines or in transgenic mouse models of tumorigenesis results in upregulated lymphangiogenesis and in the formation of lymph node metastasis [15]. The role of lymphangiogenesis and angiogenesis in breast cancer metastasis is a major focus of current research. Mammary overexpression of the blood vessel angiogenic factor VEGF-A markedly accelerates the formation of lung metastasis in MMTV-PyMT mice, not only by promoting tumor angiogenesis but also by sustaining tumor proliferation and survival [91]. In a xenograft tumor transplantation model using MDA-MB-231 breast cancer cell line variants with brain tropism, the formation of brain metastases seems highly dependent on the presence of VEGF-A [92]. Moreover, in orthotopic xenograft transplantation of human breast cancer cells with high or low metastatic ability (MDA-MB-435 and MCF-7, respectively), overexpression of VEGF-C induces intra-tumoral lymphoangiogenesis and the subsequent formation of lymph node and lung metastasis $[93,94]$. Blockade of VEGF receptor-3 signaling by specific antibodies inhibits regional and distant lymph node metastasis in these models, whereas VEGF receptor-2 inhibition results in a suppression of angiogenesis and tumor growth. Notably, a combination of the two treatments suppresses the formation of metastases better than single treatments [95]. These results indicate that angiogenic and lymphangiogenic factors may have central roles in defining organ-specific breast cancer metastasis.

\section{Conclusion}

Elucidation of the molecular mechanisms underlying breast cancer progression and metastasis has gained tremendously from mouse models in which the multiple stages of tumor progression are recapitulated. However, despite their obvious convenience in basic cancer research and in the testing of experimental therapies, the use of mouse models carries several limitations. There are obvious differences between human and mouse tumorigenesis, among which are the kinetics of carcinogenesis and the final size of tumors, differences in cell intrinsic features such as the requirements to transform cells, and differences in organ-specific gene expression, in physiology, metabolism, pathology, and in the immune system. Moreover, metastatic dissemination occurs mainly via hematogenous spreading to lungs and lymph nodes in MMTV-PyMT and MMTV-Neu mice, as opposed to the initial spreading of cancer cells to local lymph nodes via the lymphatics in human breast cancer.

Another important aspect to the understanding of breast cancer metastasis is the role of different subpopulations of breast cells, including cancer stem cells. A great effort is put into their isolation by means of molecular markers or functional assays. The use of transplanted breast cancer stem cells isolated from mice harboring different genetic modifications thereby offers a valuable tool not only in the unraveling of breast cancer development but also in designing effective therapeutic strategies.

Recent technological advances have greatly improved the use of animal models in breast cancer research, such as the use of bioluminescence and fluorescence systems, magnetic resonance, positron-enhanced tomography scans or in vivo confocal analysis to image tumor development in live animals, also allowing observation for long periods. Moreover, extended time-lapse observation of labeled tumor cells in vivo provides new insights into the actual dynamics of tumor growth, extravasation, cell migration, and organ colonization, as well as the contribution of the tumor stroma and subsets of 
immune cells. Finally, gene expression analysis of tumor samples matched with normal tissue from patients will provide gene signatures that will have to be tested in vivo by proof-of-concept experiments in reliable mouse models of breast cancer metastasis.

In the future it will be necessary to generate mouse models that more accurately recapitulate human breast carcinogenesis, while offering the advantages of model systems, such as easy genetic or pharmacological manipulation and imaging. The quest for such improved models has just begun.

\section{Competing interests}

The authors declare that they have no competing interests.

\section{Acknowledgements}

We are grateful to Dr Miguel Cabrita and Dr Francois Lehembre for critical comments on the manuscript, and to Dr Jos Jonkers for sharing unpublished results. Research in the laboratory of the authors is supported by the Krebsliga Beider Basel, Novartis Pharma Inc., NCCR Molecular Oncology, the Swiss National Science Foundation and the EU-FP6 framework programs LYMPHANGIOGENOMICS LSHG-CT2004-503573 and BRECOSM LSHC-CT-2004-503224.

\section{References}

1. Weigelt B, Peterse JL, van 't Veer LJ: Breast cancer metastasis: markers and models. Nat Rev Cancer 2005, 5:591-602.

2. Fisher B, Bauer M, Wickerham DL, Redmond CK, Fisher ER, Cruz $A B$, Foster R, Gardner B, Lerner H, Margolese R, et al.: Relation of number of positive axillary nodes to the prognosis of patients with primary breast cancer. An NSABP update. Cancer 1983, 52:1551-1557.

3. Chambers AF, Groom AC, MacDonald IC: Dissemination and growth of cancer cells in metastatic sites. Nat Rev Cancer 2002, 2:563-572.

4. Hanahan D, Weinberg RA: The hallmarks of cancer. Cell 2000, 100:57-70.

5. Hennighausen L, Robinson GW: Think globally, act locally: the making of a mouse mammary gland. Genes Dev 1998, 12: 449-455.

6. Wiseman BS, Werb Z: Stromal effects on mammary gland development and breast cancer. Science 2002, 296:1046-1049.

7. Li Y, Hively WP, Varmus HE: Use of MMTV-Wnt-1 transgenic mice for studying the genetic basis of breast cancer. Oncogene 2000, 19:1002-1009.

8. Siegel PM, Massagué J: Cytostatic and apoptotic actions of TGF-beta in homeostasis and cancer. Nat Rev Cancer 2003, 3: 807-821.

9. Pollak MN, Schernhammer ES, Hankinson SE: Insulin-like growth factors and neoplasia. Nat Rev Cancer 2004, 4:505-518.

10. Hynes NE, Lane HA: ERBB receptors and cancer: the complexity of targeted inhibitors. Nat Rev Cancer 2005, 5:341-354.

11. Cavallaro U, Christofori G: Cell adhesion and signalling by cadherins and Ig-CAMs in cancer. Nat Rev Cancer 2004, 4:118-132.

12. Lopez Jl, Camenisch TD, Stevens MV, Sands BJ, McDonald J, Schroeder JA: CD44 attenuates metastatic invasion during breast cancer progression. Cancer Res 2005, 65:6755-6763.

13. Ferrara N, Kerbel RS: Angiogenesis as a therapeutic target. Nature 2005, 438:967-974.

14. Weidner N: Tumoural vascularity as a prognostic factor in cancer patients: the evidence continues to grow. I Pathol 1998, 184:119-122.

15. Alitalo K, Tammela T, Petrova TV: Lymphangiogenesis in development and human disease. Nature 2005, 438:946-953.

16. Khanna $\mathrm{C}$, Hunter $\mathrm{K}$ : Modeling metastasis in vivo. Carcinogenesis 2005, 26:513-523.

17. Gravekamp C, Sypniewska R, Gauntt S, Tarango M, Price P, Reddick R: Behavior of metastatic and nonmetastatic breast tumors in old mice. Exp Biol Med (Maywood) 2004, 229:665675.
18. Ottewell PD, Coleman RE, Holen I: From genetic abnormality to metastases: murine models of breast cancer and their use in the development of anticancer therapies. Breast Cancer Res Treat 2005:1-13.

19. Aslakson CJ, Miller FR: Selective events in the metastatic process defined by analysis of the sequential dissemination of subpopulations of a mouse mammary tumor. Cancer Res 1992, 52:1399-1405.

20. Yang J, Mani SA, Donaher JL, Ramaswamy S, Itzykson RA, Come C, Savagner P, Gitelman I, Richardson A, Weinberg RA: Twist, a master regulator of morphogenesis, plays an essential role in tumor metastasis. Cell 2004, 117:927-939.

21. Torrero MN, Henk WG, Li S: Regression of high-grade malignancy in mice by bleomycin and interleukin-12 electrochemogenetherapy. Clin Cancer Res 2006, 12:257-263.

22. Hurst J, Maniar N, Tombarkiewicz J, Lucas F, Roberson C, Steplewski Z, James W, Perras J: A novel model of a metastatic human breast tumour xenograft line. $\mathrm{Br} J$ Cancer 1993, 68: 274-276.

23. Kim JB, O'Hare MJ, Stein R: Models of breast cancer: is merging human and animal models the future? Breast Cancer Res 2004, 6:22-30.

24. Yoneda T, Michigami T, Yi B, Williams PJ, Niewolna M, Hiraga T: Actions of bisphosphonate on bone metastasis in animal models of breast carcinoma. Cancer 2000, 88:2979-2988.

25. Kang Y, Siegel PM, Shu W, Drobnjak M, Kakonen SM, CordonCardo C, Guise TA, Massagué J: A multigenic program mediating breast cancer metastasis to bone. Cancer Cell 2003, 3: 537-549.

26. Adwan H, Bauerle TJ, Berger MR: Downregulation of osteopontin and bone sialoprotein II is related to reduced colony formation and metastasis formation of MDA-MB-231 human breast cancer cells. Cancer Gene Ther 2004, 11:109-120.

27. Minn AJ, Gupta GP, Siegel PM, Bos PD, Shu W, Giri DD, Viale A, Olshen AB, Gerald WL, Massagué J: Genes that mediate breast cancer metastasis to lung. Nature 2005, 436:518-524.

28. Orimo A, Gupta PB, Sgroi DC, Arenzana-Seisdedos F, Delaunay T, Naeem R, Carey VJ, Richardson AL, Weinberg RA: Stromal fibroblasts present in invasive human breast carcinomas promote tumor growth and angiogenesis through elevated SDF-1/CXCL12 secretion. Cel/ 2005, 121:335-348.

29. Cabioglu N, Summy J, Miller C, Parikh NU, Sahin AA, Tuzlali S, Pumiglia K, Gallick GE, Price JE: CXCL-12/stromal cell-derived factor-1alpha transactivates HER2-neu in breast cancer cells by a novel pathway involving Src kinase activation. Cancer Res 2005, 65:6493-6497.

30. Kuperwasser C, Dessain S, Bierbaum BE, Garnet D, Sperandio K, Gauvin GP, Naber SP, Weinberg RA, Rosenblatt M: A mouse model of human breast cancer metastasis to human bone. Cancer Res 2005, 65:6130-6138.

31. Stewart TA, Pattengale PK, Leder P: Spontaneous mammary adenocarcinomas in transgenic mice that carry and express MTV/myc fusion genes. Cell 1984, 38:627-637.

32. Schoenenberger CA, Andres AC, Groner B, van der Valk M, LeMeur M, Gerlinger P: Targeted c-myc gene expression in mammary glands of transgenic mice induces mammary tumours with constitutive milk protein gene transcription. EMBO J 1988, 7:169-175.

33. Sandgren EP, Schroeder JA, Qui TH, Palmiter RD, Brinster RL, Lee DC: Inhibition of mammary gland involution is associated with transforming growth factor alpha but not c-myc-induced tumorigenesis in transgenic mice. Cancer Res 1995, 55:39153927.

34. Cardiff RD, Anver MR, Gusterson BA, Hennighausen L, Jensen RA, Merino MJ, Rehm S, Russo J, Tavassoli FA, Wakefield LM, et al.: The mammary pathology of genetically engineered mice: the consensus report and recommendations from the Annapolis meeting. Oncogene 2000, 19:968-988.

35. Sinn E, Muller W, Pattengale P, Tepler I, Wallace R, Leder P: Coexpression of MMTV/v-Ha-ras and MMTV/c-myc genes in transgenic mice: synergistic action of oncogenes in vivo. Cell 1987, 49:465-475.

36. Green JE, Shibata MA, Yoshidome K, Liu ML, Jorcyk C, Anver MR, Wigginton J, Wiltrout R, Shibata E, Kaczmarczyk S, et al:: The C3(1)/SV40 T-antigen transgenic mouse model of mammary cancer: ductal epithelial cell targeting with multistage progression to carcinoma. Oncogene 2000, 19:1020-1027. 
37. Gossen M, Bujard H: Tight control of gene expression in mammalian cells by tetracycline-responsive promoters. Proc Natl Acad Sci USA 1992, 89:5547-5551.

38. Gunther EJ, Belka GK, Wertheim GB, Wang J, Hartman JL, Boxer $\mathrm{RB}$, Chodosh LA: A novel doxycycline-inducible system for the transgenic analysis of mammary gland biology. FASEB J 2002, 16:283-292

39. Sauer B, Henderson N: Cre-stimulated recombination at loxPcontaining DNA sequences placed into the mammalian genome. Nucleic Acids Res 1989, 17:147-161.

40. Wagner KU, Wall RJ, St-Onge L, Gruss P, Wynshaw-Boris A, Garrett L, Li M, Furth PA, Hennighausen L: Cre-mediated gene deletion in the mammary gland. Nucleic Acids Res 1997, 25: 4323-4330

41. Desai KV, Xiao N, Wang W, Gangi L, Greene J, Powell Jl, Dickson $\mathrm{R}$, Furth $\mathrm{P}$, Hunter K, Kucherlapati R, et al.: Initiating oncogenic event determines gene-expression patterns of human breast cancer models. Proc Natl Acad Sci USA 2002, 99:6967-6972.

42. Muller WJ, Sinn E, Pattengale PK, Wallace R, Leder P: Singlestep induction of mammary adenocarcinoma in transgenic mice bearing the activated c-neu oncogene. Cell 1988, 54: 105-115.

43. Moody SE, Perez D, Pan TC, Sarkisian CJ, Portocarrero CP, Sterner CJ, Notorfrancesco KL, Cardiff RD, Chodosh LA: The transcriptional repressor Snail promotes mammary tumor recurrence. Cancer Cell 2005, 8:197-209.

44. Dankort D, Maslikowski B, Warner N, Kanno N, Kim H, Wang Z, Moran MF, Oshima RG, Cardiff RD, Muller WJ: Grb2 and Shc adapter proteins play distinct roles in Neu (ErbB-2)-induced mammary tumorigenesis: implications for human breast cancer. Mol Cell Biol 2001, 21:1540-1551.

45. Guy CT, Cardiff RD, Muller WJ: Induction of mammary tumors by expression of polyomavirus middle $\mathrm{T}$ oncogene: a transgenic mouse model for metastatic disease. Mol Cell Biol 1992, 12:954-961.

46. Lin EY, Jones JG, Li P, Zhu L, Whitney KD, Muller WJ, Pollard JW: Progression to malignancy in the polyoma middle T oncoprotein mouse breast cancer model provides a reliable model for human diseases. Am J Pathol 2003, 163:2113-2126.

47. Maglione JE, Moghanaki D, Young LJ, Manner CK, Ellies LG, Joseph SO, Nicholson B, Cardiff RD, MacLeod CL: Transgenic Polyoma middle-T mice model premalignant mammary disease. Cancer Res 2001, 61:8298-8305.

48. Lin EY, Nguyen AV, Russell RG, Pollard JW: Colony-stimulating factor 1 promotes progression of mammary tumors to malignancy. J Exp Med 2001, 193:727-740.

49. Wyckoff J, Wang W, Lin EY, Wang Y, Pixley F, Stanley ER, Graf T, Pollard JW, Segall J, Condeelis J: A paracrine loop between tumor cells and macrophages is required for tumor cell migration in mammary tumors. Cancer Res 2004, 64:70227029.

50. Gouon-Evans V, Rothenberg ME, Pollard JW: Postnatal mammary gland development requires macrophages and eosinophils. Development 2000, 127:2269-2282.

51. Almholt K, Lund LR, Rygaard J, Nielsen BS, Dano K, Romer J, Johnsen M: Reduced metastasis of transgenic mammary cancer in urokinase-deficient mice. Int J Cancer 2005, 113: 525-532.

52. Bugge TH, Lund LR, Kombrinck KK, Nielsen BS, Holmback K, Drew AF, Flick MJ, Witte DP, Dano K, Degen JL: Reduced metastasis of Polyoma virus middle $T$ antigen-induced mammary cancer in plasminogen-deficient mice. Oncogene 1998, 16:3097-3104.

53. Cuevas BD, Winter-Vann AM, Johnson NL, Johnson GL: MEKK1 controls matrix degradation and tumor cell dissemination during metastasis of polyoma middle-T driven mammary cancer. Oncogene 2006.

54. Schroeder JA, Adriance MC, Thompson MC, Camenisch TD, Gendler SJ: MUC1 alters beta-catenin-dependent tumor formation and promotes cellular invasion. Oncogene 2003, 22: 1324-1332.

55. Hoffman RM: Green fluorescent protein imaging of tumor cells in mice. Lab Anim (NY) 2002, 31:34-41.

56. Ahmed F, Wyckoff J, Lin EY, Wang W, Wang Y, Hennighausen L, Miyazaki J, Jones J, Pollard JW, Condeelis JS, et al.: GFP expression in the mammary gland for imaging of mammary tumor cells in transgenic mice. Cancer Res 2002, 62:7166-7169.
57. Lyons SK, Meuwissen R, Krimpenfort $P$, Berns A: The generation of a conditional reporter that enables bioluminescence imaging of Cre/loxP-dependent tumorigenesis in mice. Cancer Res 2003, 63:7042-7046.

58. Kawamoto S, Niwa H, Tashiro F, Sano S, Kondoh G, Takeda J, Tabayashi $\mathrm{K}$, Miyazaki J: A novel reporter mouse strain that expresses enhanced green fluorescent protein upon Cremediated recombination. FEBS Lett 2000, 470:263-268.

59. Dubey P, Su H, Adonai N, Du S, Rosato A, Braun J, Gambhir SS, Witte ON: Quantitative imaging of the $\mathrm{T}$ cell antitumor response by positron-emission tomography. Proc Natl Acad Sci USA 2003, 100:1232-1237.

60. Naumov GN, Wilson SM, MacDonald IC, Schmidt EE, Morris VL, Groom AC, Hoffman RM, Chambers AF: Cellular expression of green fluorescent protein, coupled with high-resolution in vivo videomicroscopy, to monitor steps in tumor metastasis. $J \mathrm{Cell}$ Sci 1999, 112:1835-1842.

61. Sweeney TJ, Mailander V, Tucker AA, Olomu AB, Zhang W, Cao $\mathrm{Y}$, Negrin RS, Contag $\mathrm{CH}$ : Visualizing the kinetics of tumor-cell clearance in living animals. Proc Natl Acad Sci USA 1999, 96: 12044-12049.

62. Condeelis J, Segall JE: Intravital imaging of cell movement in tumours. Nat Rev Cancer 2003, 3:921-930.

63. Chambers AF, MacDonald IC, Schmidt EE, Koop S, Morris VL, Khokha R, Groom AC: Steps in tumor metastasis: new concepts from intravital videomicroscopy. Cancer Metastasis Rev 1995, 14:279-301.

64. Georgakoudi I, Solban N, Novak J, Rice WL, Wei X, Hasan T, Lin $\mathrm{CP}$ : In vivo flow cytometry: a new method for enumerating circulating cancer cells. Cancer Res 2004, 64:5044-5047.

65. Yin JJ, Selander K, Chirgwin JM, Dallas M, Grubbs BG, Wieser R Massagué J, Mundy GR, Guise TA: TGF-beta signaling blockade inhibits PTHrP secretion by breast cancer cells and bone metastases development. J Clin Invest 1999, 103:197-206.

66. Muraoka RS, Koh Y, Roebuck LR, Sanders ME, Brantley-Sieders D, Gorska AE, Moses HL, Arteaga CL: Increased malignancy of Neu-induced mammary tumors overexpressing active transforming growth factor beta1. Mol Cell Biol 2003, 23:86918703.

67. Siegel PM, Shu W, Cardiff RD, Muller WJ, Massagué J: Transforming growth factor beta signaling impairs Neu-induced mammary tumorigenesis while promoting pulmonary metastasis. Proc Natl Acad Sci USA 2003, 100:8430-8435.

68. Muraoka-Cook RS, Kurokawa H, Koh Y, Forbes JT, Roebuck LR, Barcellos-Hoff MH, Moody SE, Chodosh LA, Arteaga CL: Conditional overexpression of active transforming growth factor beta1 in vivo accelerates metastases of transgenic mammary tumors. Cancer Res 2004, 64:9002-9011.

69. Forrester E, Chytil A, Bierie B, Aakre M, Gorska AE, Sharif-Afshar AR, Muller WJ, Moses HL: Effect of conditional knockout of the type II TGF-beta receptor gene in mammary epithelia on mammary gland development and polyomavirus middle T antigen induced tumor formation and metastasis. Cancer Res 2005, 65:2296-2302.

70. Yang YA, Dukhanina O, Tang B, Mamura M, Letterio JJ, MacGregor J, Patel SC, Khozin S, Liu ZY, Green J, et al.: Lifetime exposure to a soluble TGF-beta antagonist protects mice against metastasis without adverse side effects. J Clin Invest 2002, 109:1607-1615.

71. Dumont N, Arteaga CL: Targeting the TGF beta signaling network in human neoplasia. Cancer Cell 2003, 3:531-536.

72. Pierce DF Jr, Gorska AE, Chytil A, Meise KS, Page DL, Coffey RJ $\mathrm{Jr}$, Moses HL: Mammary tumor suppression by transforming growth factor beta 1 transgene expression. Proc Natl Acad Sci USA 1995, 92:4254-4258.

73. Ross JS, Fletcher JA: The HER-2/neu oncogene in breast cancer: prognostic factor, predictive factor, and target for therapy. Stem Cells 1998, 16:413-428.

74. Zhang G, He B, Weber GF: Growth factor signaling induces metastasis genes in transformed cells: molecular connection between Akt kinase and osteopontin in breast cancer. Mol Cell Biol 2003, 23:6507-6519.

75. Xue C, Liang F, Mahmood R, Vuolo M, Wyckoff J, Qian H, Tsai KL, Kim M, Locker J, Zhang ZY, Segall JE: ErbB3-dependent motility and intravasation in breast cancer metastasis. Cancer Res 2006, 66:1418-1426.

76. Xue C, Wyckoff J, Liang F, Sidani M, Violini S, Tsai KL, Zhang ZY, 
Sahai E, Condeelis J, Segall JE: Epidermal growth factor receptor overexpression results in increased tumor cell motility in vivo coordinately with enhanced intravasation and metastasis. Cancer Res 2006, 66:192-197.

77. Kwan H, Pecenka V, Tsukamoto A, Parslow TG, Guzman R, Lin TP, Muller WJ, Lee FS, Leder P, Varmus HE: Transgenes expressing the Wnt-1 and int-2 proto-oncogenes cooperate during mammary carcinogenesis in doubly transgenic mice. Mol Cell Biol 1992, 12:147-154.

78. Kolonin M, Pasqualini R, Arap W: Molecular addresses in blood vessels as targets for therapy. Curr Opin Chem Biol 2001, 5: 308-313.

79. Fidler IJ: The organ microenvironment and cancer metastasis. Differentiation 2002, 70:498-505.

80. Muller A, Homey B, Soto H, Ge N, Catron D, Buchanan ME, McClanahan T, Murphy E, Yuan W, Wagner SN, et al.: Involvement of chemokine receptors in breast cancer metastasis. Nature 2001, 410:50-56.

81. Liang Z, Yoon Y, Votaw J, Goodman MM, Williams L, Shim H: Silencing of CXCR4 blocks breast cancer metastasis. Cancer Res 2005, 65:967-971.

82. Liang Z, Wu T, Lou H, Yu X, Taichman RS, Lau SK, Nie S, Umbreit J, Shim H: Inhibition of breast cancer metastasis by selective synthetic polypeptide against CXCR4. Cancer Res 2004, 64:4302-4308.

83. Tuck $A B$, Arsenault DM, O'Malley FP, Hota C, Ling MC, Wilson $\mathrm{SM}$, Chambers AF: Osteopontin induces increased invasiveness and plasminogen activator expression of human mammary epithelial cells. Oncogene 1999, 18:4237-4246.

84. Khan SA, Cook AC, Kappil M, Gunthert U, Chambers AF, Tuck $A B$, Denhardt DT: Enhanced cell surface CD44 variant (v6, v9) expression by osteopontin in breast cancer epithelial cells facilitates tumor cell migration: novel post-transcriptional, post-translational regulation. Clin Exp Metastasis 2006.

85. Lee H, Lin EC, Liu L, Smith JW: Gene expression profiling of tumor xenografts: in vivo analysis of organ-specific metastasis. Int J Cancer 2003, 107:528-534.

86. Vantyghem SA, Allan AL, Postenka CO, Al-Katib W, Keeney M, Tuck AB, Chambers AF: A new model for lymphatic metastasis: development of a variant of the MDA-MB-468 human breast cancer cell line that aggressively metastasizes to lymph nodes. Clin Exp Metastasis 2005, 22:351-361.

87. Saito H, Tsunenari T, Onuma E, Sato K, Ogata E, Yamada-Okabe $\mathrm{H}$ : Humanized monoclonal antibody against parathyroid hormone-related protein suppresses osteolytic bone metastasis of human breast cancer cells derived from MDA-MB-231. Anticancer Res 2005, 25:3817-3823.

88. Jones $\mathrm{DH}$, Nakashima $\mathrm{T}$, Sanchez $\mathrm{OH}$, Kozieradzki I, Komarova SV, Sarosi I, Morony S, Rubin E, Sarao R, Hojilla CV, et al.: Regulation of cancer cell migration and bone metastasis by RANKL. Nature 2006, 440:692-696.

89. Morony S, Capparelli C, Sarosi I, Lacey DL, Dunstan CR, Kostenuik PJ: Osteoprotegerin inhibits osteolysis and decreases skeletal tumor burden in syngeneic and nude mouse models of experimental bone metastasis. Cancer Res 2001, 61:4432-4436.

90. Fisher JL, Thomas-Mudge RJ, Elliott J, Hards DK, Sims NA, Slavin J, Martin TJ, Gillespie MT: Osteoprotegerin overexpression by breast cancer cells enhances orthotopic and osseous tumor growth and contrasts with that delivered therapeutically. Cancer Res 2006, 66:3620-3628.

91. Schoeffner DJ, Matheny SL, Akahane T, Factor V, Berry A, Merlino G, Thorgeirsson UP: VEGF contributes to mammary tumor growth in transgenic mice through paracrine and autocrine mechanisms. Lab Invest 2005, 85:608-623.

92. Kim LS, Huang S, Lu W, Lev DC, Price JE: Vascular endothelial growth factor expression promotes the growth of breast cancer brain metastases in nude mice. Clin Exp Metastasis 2004, 21:107-118.

93. Skobe M, Hawighorst $T$, Jackson DG, Prevo R, Janes $L$, Velasco $P$, Riccardi L, Alitalo K, Claffey K, Detmar M: Induction of tumor lymphangiogenesis by VEGF-C promotes breast cancer metastasis. Nat Med 2001, 7:192-198.

94. Mattila MM, Ruohola JK, Karpanen T, Jackson DG, Alitalo K, Harkonen PL: VEGF-C induced lymphangiogenesis is associated with lymph node metastasis in orthotopic MCF-7 tumors. Int J Cancer 2002, 98:946-951.
95. Roberts N, Kloos B, Cassella M, Podgrabinska S, Persaud K, Wu Y, Pytowski B, Skobe M: Inhibition of VEGFR-3 activation with the antagonistic antibody more potently suppresses lymph node and distant metastases than inactivation of VEGFR-2. Cancer Res 2006, 66:2650-2657.

96. Hennighausen L: The mammary gland as a bioreactor: production of foreign proteins in milk. Protein Expr Purif 1990, 1:3-8.

97. Lipnik K, Petznek H, Renner-Muller I, Egerbacher M, Url A Salmons B, Gunzburg WH, Hohenadl C: A 470 bp WAP-promoter fragment confers lactation independent, progesterone regulated mammary-specific gene expression in transgenic mice. Transgenic Res 2005, 14:145-158.

98. Ali S, Clark AJ: Characterization of the gene encoding ovine beta-lactoglobulin. Similarity to the genes for retinol binding protein and other secretory proteins. J Mol Biol 1988, 199: 415-426.

99. Bortner DM, Rosenberg MP: Induction of mammary gland hyperplasia and carcinomas in transgenic mice expressing human cyclin E. Mol Cell Biol 1997, 17:453-459.

100. Palmiter RD, Sandgren EP, Koeller DM, Brinster RL: Distal regulatory elements from the mouse metallothionein locus stimulate gene expression in transgenic mice. Mol Cell Biol 1993, 13:5266-5275.

101. Liu CH, Chang SH, Narko K, Trifan OC, Wu MT, Smith E, Haudenschild C, Lane TF, Hla T: Overexpression of cyclooxygenase-2 is sufficient to induce tumorigenesis in transgenic mice. J Biol Chem 2001, 276:18563-18569.

102. Guy CT, Webster MA, Schaller M, Parsons TJ, Cardiff RD, Muller WJ: Expression of the neu protooncogene in the mammary epithelium of transgenic mice induces metastatic disease. Proc Natl Acad Sci USA 1992, 89:10578-10582.

103. Moody SE, Sarkisian CJ, Hahn KT, Gunther EJ, Pickup S, Dugan KD, Innocent N, Cardiff RD, Schnall MD, Chodosh LA: Conditional activation of $\mathrm{Neu}$ in the mammary epithelium of transgenic mice results in reversible pulmonary metastasis. Cancer Cell 2002, 2:451-461.

104. Jeffers M, Fiscella M, Webb CP, Anver M, Koochekpour S, Vande Woude GF: The mutationally activated Met receptor mediates motility and metastasis. Proc Natl Acad Sci USA 1998, 95: 14417-14422.

105. Maroulakou IG, Anver M, Garrett L, Green JE: Prostate and mammary adenocarcinoma in transgenic mice carrying a rat C3(1) simian virus 40 large tumor antigen fusion gene. Proc Natl Acad Sci USA 1994, 91:11236-11240.

106. Gallahan D, Jhappan C, Robinson G, Hennighausen L, Sharp R, Kordon E, Callahan R, Merlino G, Smith GH: Expression of a truncated Int3 gene in developing secretory mammary epithelium specifically retards lobular differentiation resulting in tumorigenesis. Cancer Res 1996, 56:1775-1785.

107. Schulze-Garg C, Lohler J, Gocht A, Deppert W: A transgenic mouse model for the ductal carcinoma in situ (DCIS) of the mammary gland. Oncogene 2000, 19:1028-1037.

108. Nielsen LL, Discafani CM, Gurnani M, Tyler RD: Histopathology of salivary and mammary gland tumors in transgenic mice expressing a human Ha-ras oncogene. Cancer Res 1991, 51 3762-3767.

109. Gallego Ml, Bierie B, Hennighausen L: Targeted expression of HGF/SF in mouse mammary epithelium leads to metastatic adenosquamous carcinomas through the activation of multiple signal transduction pathways. Oncogene 2003, 22:84988508.

110. Pravtcheva DD, Wise TL: Metastasizing mammary carcinomas in $\mathrm{H} 19$ enhancers-lgf2 transgenic mice. J Exp Zool 1998, 281: 43-57.

111. Lin SC, Lee KF, Nikitin AY, Hilsenbeck SG, Cardiff RD, Li A, Kang KW, Frank SA, Lee WH, Lee EY: Somatic mutation of p53 leads to estrogen receptor alpha-positive and -negative mouse mammary tumors with high frequency of metastasis. Cancer Res 2004, 64:3525-3532.

112. Ridgeway AG, McMenamin J, Leder P: P53 levels determine outcome during beta-catenin tumor initiation and metastasis in the mammary gland and male germ cells. Oncogene 2006.

113. Davies MP, Rudland PS, Robertson L, Parry EW, Jolicoeur P, Barraclough R: Expression of the calcium-binding protein S100A4 (p9Ka) in MMTV-neu transgenic mice induces metastasis of mammary tumours. Oncogene 1996, 13:1631-1637. 